\title{
La recuperación de la naturaleza por el aislamiento social debido al Covid-19 ¿Realidad o ficción?
}

\section{The recovery of nature through social isolation by Covid-19 ¿Reality or fiction?}

\author{
J. Selva Andina Res. Soc. 2020;11(2):60-61.
}

The world today is threatened by a new pandemic, which originated in China at the end of 2019. Countries have applied social isolation as an emergency and control measure, which has led to a decrease in the presence of human beings in their normal activities. Sometime after the isolation, sightings were reported through different media in different countries on all continents, of animals in places reserved for humans, such as streets, residential complexes, highways, and parks, as well as evidence of clearer water in rivers and coasts, which has caused a series of reactions, which mainly talk about how nature recovers and reclaims the places that were taken away from it by man and some say that the environment is improving and purifying because it is being less intervened by humans confined and isolated from the environment.

Although the images of animals walking in the main cities of the world or the water clarified by the little traffic of boats, which are anchored in the ports, are impressive, it is pertinent to ask oneself the questions: Is this apparent recovery of the environment real or fictitious? What will happen when the man returns to his normal activities?

Although it is a reality that social isolation has given "a break" to the environment, this is limited to what the media shows us, however, it is clear that most of the industrial activities that cause greater negative environmental impacts have not been stopped and not only that but they have done so in an environment of little control since social isolation has led to the media and environmental defense organizations not having access to these industries and their activities, so they operate with the complicity of the historical moment, damaging the environment without their effects being disclosed or communicated. Thus, the oil industry continues to contaminate soil, water, and air all over the world, the mining industry continues to pollute with the generation of highly toxic tailings, the lumber industry continues to go unchecked destroying the forests and jungles that are the generators of the planet's oxygen, the chemical industries continue to dump their effluents into rivers, lakes, and seas, under the protection of governments eager to try to control the pandemic, at all costs. From the very moment that Covid-19 was declared a pandemic by the World Health Organization, economists around the world have been heard talking about the negative impact of social isolation on the economy of countries, which is evident, especially in countries that depend on trade and the exploitation of their natural resources, as is the particular case of the countries of Latin America and the Caribbean. This indicates that even when nature shows an apparent recovery, once social isolation ceases, the countries will have to return to their normal activities and these will be magnified to achieve the recovery of their economies, which were hit by the measures taken in the pandemic, in the shortest possible time. It is obvious, then, that the outlook for nature is not very promising, since extractive activities, which generate the massive consumption of natural resources, will be increased, which will cause a significant environmental impact, perhaps reversing all the recovery that could have occurred in nature during social isolation.

From there, the recovery of nature in times of pandemic, even though it is a reality shown to us by the media, is not so real, because man is stealthily continuing to degrade the environment, under the distraction that Covid-19 has created for its industrial activities, which will be accentuated in the future when social isolation is lifted, with the excuse of the 
economic recovery of countries. This requires serious and independent studies that investigate the true impact of the pandemic on the environment, which can minimize the negative effects that are being hailed, and that will increase in the future if the corresponding measures are not taken.

Tomás Darío Marín Velásquez

Innova Scientific SAC Scientific Production Management.

Department of Investigation.

Av. la Marina 1453.

San Miguel 15086

Lima, Perú

Tel: (01)6768070/948631287.

Informes@innovascientific.com

tmarin@innovascientific.com 